2. Ramay FH, Vareedayah AA, Visrodia K, Iyer PG, Wang KK, Eluri S, et al. What constitutes optimal management of T1N0 esophageal adenocarcinoma? Ann Surg Oncol. 2019;26:714-31.
3. Marino KA, Sullivan JL, Weksler B. Esophagectomy versus endoscopic resection for patients with early-stage esophageal adenocarcinoma: a national cancer database propensity-matched study. J Thorac Cardiovasc Surg. 2018;155:2211-8.
See Article page 1272.

\section{Commentary: Risk stratification for superficial esophageal adenocarcinoma: Reducing risk in a risky business!}

\author{
Saurav Adhikari, MD, and Siva Raja, MD, PhD, FACS
}

Organ preservation in the treatment of early esophageal cancer is an accepted paradigm. These techniques are appropriate for carefully selected patients who have earlystage and less aggressive tumors or as a mitigating measure. ${ }^{1}$ Unlike some other malignancies for which the aggressiveness of the cancer, such as lung cancer, can span the spectrum of indolent to aggressive, esophageal adenocarcinoma mostly has aggressive and very aggressive biology. As such, only the earliest of cancers have a low enough risk of metastatic spread at the time of diagnosis that they can be treated with local therapies. However, the identification of this "low-risk" population has remained elusive.

In their article, Sihag and colleagues ${ }^{2}$ have attempted to define criteria associated with a low risk of cancer recurrence in pT1 esophageal adenocarcinoma. In the univariable analysis, they identified the usual suspects for increased risk, such as submucosal invasion, poor differentiation, nodal disease, increased tumor length, and multicentricity. However, using a multivariable model, the authors have demonstrated only increased tumor length and nodal disease to be independent risk factors for recurrence. More interestingly, they set out to identify cancers

\footnotetext{
From the Department of Thoracic and Cardiovascular Surgery, Heart and Vascular Institute, Cleveland Clinic, Cleveland, Ohio.

Disclosures: The authors reported no conflicts of interest.

The Journal policy requires editors and reviewers to disclose conflicts of interest and to decline handling or reviewing manuscripts for which they may have a conflict of interest. The editors and reviewers of this article have no conflicts of interest.

Received for publication Nov 20, 2020; revisions received Nov 20, 2020; accepted for publication Nov 23, 2020; available ahead of print Dec 3, 2020.

Address for reprints: Siva Raja, MD, PhD, FACS, Department of Thoracic and Cardiovascular Surgery, Heart and Vascular Institute, Cleveland Clinic Foundation, J41, 9500 Euclid Ave, Cleveland, OH 44195 (E-mail: rajas@ccf.org).

J Thorac Cardiovasc Surg 2021;162:1281-2

$0022-5223 / \$ 36.00$

Copyright (c) 2020 by The American Association for Thoracic Surgery

https://doi.org/10.1016/j.jtcvs.2020.11.130
}

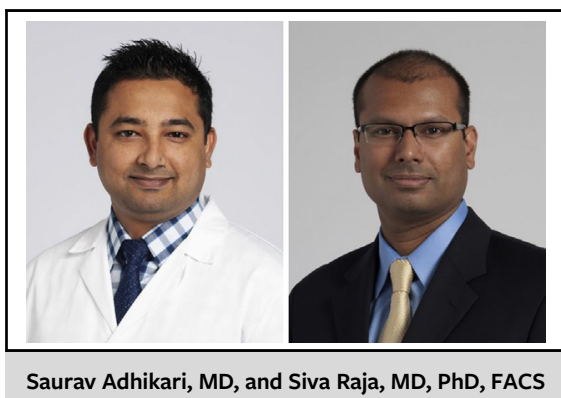

CENTRAL MESSAGE

Early-stage esophageal cancer

may be amenable to endoscopic

therapy, but requires careful

assessment of cancer

characteristics.

with less than $10 \%$ chance of recurrence on the basis of only preoperative clinicopathologic features. In doing so, they noted that patients with tumors less than $2 \mathrm{~cm}$ without lymphovascular invasion had a low rate of recurrence.

It is important to note that the patient population identified in the study includes those with completely resected cancers in whom recurrence status was retrospectively explored. Given that they have had a reasonable nodal dissection, occult metastatic disease (be it in regional lymph nodes or in transit within the esophageal lymphatics) may have been surgically removed in clinically node-negative patients. It is difficult to determine how these results would translate to recurrence in patients after endoscopic resection only in whom a lymphadenectomy had not been performed. Additionally, the authors only found N1 disease to be significant but not depth of invasion or poor differentiation to be a risk factor for recurrence. Although curious at first glance, it is likely because their study population was small, and these, at some level, are related variables.

This original work ${ }^{2}$ adds to our current knowledge base about tumors that are low risk, high risk, and everything in between. Mucosal tumors without poor differentiation or lymphovascular invasion are clearly suited to organ- 
sparing techniques, whereas those with the presence of submucosal invasion and poor differentiation are higher-risk tumors. With a closer examination, we found that submucosal esophageal cancer (pT1b) with deep submucosal invasion (SM3) and possibly lymphovascular invasion predicted regional lymph node metastases. ${ }^{3}$ As such, these patients are generally not good candidates for esophageal preservation and better suited for resection. Although endoscopic therapies are on the rise, there is a still a paucity of data on the true risk of many of these "superficial cancers." As an example, does a mucosal tumor with lymphovascular invasion have a lower risk of recurrence than SM1 cancer that is well differentiated?

Given the high morbidity of an esophagectomy, the treatment of esophageal cancers is a risky business. In this regard, endoscopic therapies reduce the risk of treatment- related morbidity in low-risk cancers. However, we must always bear in mind the risk of death posed by this aggressive disease to our patients. As such, a radical resection may be the less-risky option in the long term in high-risk cancers!

\section{References}

1. Semenkovich TR, Hudson JL, Subramanian M, Mullady DK, Meyers BF, Puri V, et al. Trends in treatment of T1N0 esophageal cancer. Ann Surg. 2019;270: 434-43.

2. Sihag S, Torre SDL, Hsu M, Nobel T, Tan KS, Gerdes H, et al. Defining low-risk lesions in early-stage esophageal adenocarcinoma. J Thorac Cardiovasc Surg. 2021;162:1272-9.

3. Raja S, Rice TW, Goldblum JR, Rybicki LA, Murthy SC, Mason DP, et al. Esophageal submucosa: the watershed for esophageal cancer. J Thorac Cardiovasc Surg. 2011;142:1403-11.e1.

4. Marino KA, Sullivan JL, Weksler B. Esophagectomy versus endoscopic resection for patients with early-stage esophageal adenocarcinoma: a national cancer database propensity-matched study. J Thorac Cardiovasc Surg. 2018;155:2211-8.e1.
See Article page 1272.

\section{Commentary: Defining low-risk lesions for esophageal preservation informed by resecting the organ}

\author{
Brian E. Louie, MD, MHA, MPH, FRCSC, FACS
}

Over 20 years ago, the first reports of endoscopic mucosal resection (EMR) for mucosal-based esophageal cancers appeared in the gastrointestinal literature ${ }^{1}$ and shortly after in the thoracic surgery literature. ${ }^{2}$ This initiated a paradigm shift in how early esophageal adenocarcinomas, particularly T1a tumors, were being managed. Endoscopic eradication therapy, mucosal resection to remove the cancerous lesion, and radiofrequency ablation ${ }^{3}$ to eradicate the precursor lesion-Barrett's esophagus-has emerged as an

From the Division of Thoracic Surgery, Swedish Medical Center, Thoracic Research Program, and Minimally Invasive Thoracic Surgery Program, Swedish Digestive Health Institute, Seattle, Wash.

Disclosures: Dr Louie has received educational grants from Boston Scientific and Medtronic.

The Journal policy requires editors and reviewers to disclose conflicts of interest and to decline handling or reviewing manuscripts for which they may have a conflict of interest. The editors and reviewers of this article have no conflicts of interest.

Received for publication Nov 23, 2020; revisions received Nov 23, 2020; accepted for publication Nov 24, 2020; available ahead of print Dec 3, 2020.

Address for reprints: Brian E. Louie, MD, MHA, MPH, FRCSC, FACS, Division of Thoracic Surgery, Swedish Medical Center, 1101 Madison St, Suite 900, Seattle, WA 98104 (E-mail: brian.louie@swedish.org).

J Thorac Cardiovasc Surg 2021;162:1282-3

$0022-5223 / \$ 36.00$

Copyright (c) 2020 by The American Association for Thoracic Surgery

https://doi.org/10.1016/j.jtcvs.2020.11.115
Check for updates

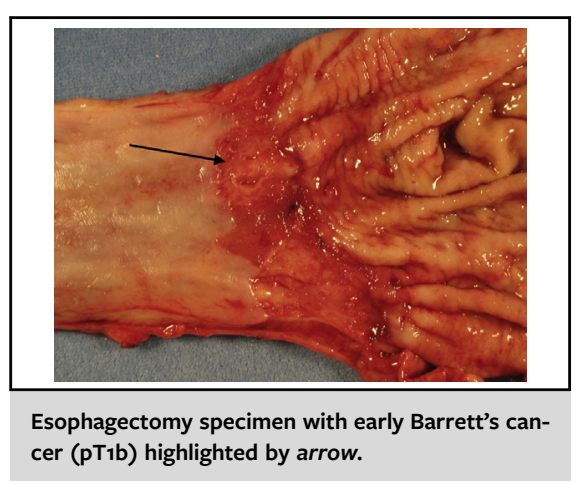

CENTRAL MESSAGE

Esophageal preservation for

early Barrett's cancers requires

knowledge of risk factors for

recurrence to select appropriate

patients. This knowledge often

comes from analysis of resected

specimens.

important treatment strategy that allows for organ preservation in patients with Barrett's-related early cancers.

The work by Sihag and colleagues ${ }^{4}$ is one of many in which surgeons through analysis of resected esophageal specimens have sought to inform our treatment of Barrett's-related cancer. Early in the development of organ- 